\title{
Do movimento negro à escola pública: como as ações afirmativas foram pensadas pelos parlamentares do Congresso Nacional
}

\author{
Luma Doné Miranda'
}

\begin{abstract}
Resumo
O objetivo deste artigo é analisar como os parlamentares pensavam as ações afirmativas no ensino superior. Para tanto, foram analisados 28 projetos de lei que objetivaram a criação desse tipo de política. Como recorte principal, buscamos apreender as justificativas apresentadas pelos deputados e senadores na hora de protocolar os projetos. Como conclusão, percebemos que apesar da luta histórica do movimento negro no Brasil por ações afırmativas, ao se discutir essa temática no Congresso Nacional, os parlamentares levaram em consideração a escola pública como um espaço que engloba tanto a discussão de classe quanto a de raça.
\end{abstract}

\author{
Palavras-chave \\ Ações Afırmativas; Cotas; Raça; Classe; Educação Pública.
}

From the black movement to the public school: how affirmative actions were conceived by parliamentarians of the National Congress

\begin{abstract}
The purpose of this article is to analyze how parliamentarians of the National Congress arguments for the creation of affirmative actions for higher education. 28 projects were reviewed through content-analysis aiming at observing the key arguments for the creation of affirmative action policies. The results demonstrate that policy-makers see these policies as a means to deal with the low quality of public education as opposed to racial issues. In conclusion, it can be observed that despite the historical struggle of the black movement in Brazil for affirmative actions, parliamentarians perceive public schools as a space that merges both the discussion of class and race.
\end{abstract}

\section{Keywords}

Affirmative Actions; Quotas; Race; Class; Public Education.

Artigo recebido: novembro de 2020

Artigo aprovado: dezembro de 2020 


\section{Introdução}

A ação afirmativa é um mecanismo que busca corrigir uma condição de desigualdade formada por processos históricos. Seu principal objetivo é assegurar a igualdade de oportunidades de grupos que sofrem preconceito (FONSECA, 2009, p. 11). Assim, sua crucial finalidade é criar um efeito compensatório através da valorização social desses grupos durante um período limitado (MOEHLECKE, 2002, p.2003).

O debate sobre ações afırmativas se inicia no Brasil com a organização de coletivos negros² a partir dos anos 40. Ainda não havia uma reivindicação por esse tipo de política, contudo, esses movimentos buscavam a valorização do negro na sociedade brasileira (ALBERTI e PEREIRA; 2006, p.146). O tema se consolida apenas em 2000 com a institucionalização de cotas nas universidades estaduais do Rio de Janeiro e com a III Conferência Mundial de Combate ao Racismo, Discriminação Racial, Xenofobia e Intolerância Correlata, realizada em Durban, África do Sul em 2002.

Distante de um consenso, o estabelecimento de ações afirmativas no ensino superior gerou grande controvérsia tanto na esfera pública e quanto na acadêmica. A discussão se centrava no público-alvo desta política, os negros ${ }^{3}$, e se desdobrava em questões como raça e identidade no Brasil, racismo, igualdade formal e queda de qualidade nas universidades (BITTAR e ALMEIDA, 2006; CAMPOS, 2008; FERES JUNIOR e DALFLON, 2015). Além disso, o debate foi deslocado ao Supremo Tribunal Federal onde o Partido da Frente Liberal (PFL) questionou a constitucionalidade das cotas raciais na Universidade de Brasília através da Arguição de Descumprimento de Preceito Fundamental (ADPF) n¹86. Contudo, em 2012, com o resultado favorável, o STF sacramentou de vez a realização desse dispositivo.

No mesmo ano, o Congresso Nacional aprovou a lei $n^{\circ} 12.711 / 12$ que ficou conhecida como "lei de cotas". Oriunda do projeto de lei $n^{\circ}$ $73 / 99^{4}$, a proposta tramitou durante 13 anos nas casas legislativas e seu 
desenho final é uma combinação de outros PLs apensados durante o processo (MIRANDA, 2018, p. 105). Como resultado, a legislação ordena a reserva de $50 \%$ das vagas nas universidades federais brasileiras para estudantes oriundos de escola pública e possui duas subcotas para pessoas com renda abaixo de 1,5 salário-mínimo, pretos, pardos e indígenas (BRASIL, 2012) ${ }^{5}$.

O presente trabalho se insere nesse contexto, sua motivação ocorreu a partir do questionamento do desenho apresentado pela lei de cotas e das discussões sobre o tema no movimento negro. Compreendemos que apesar da luta histórica, a lei $n^{\circ}$ 12.711/12 refletiu muito mais as discussões que ocorriam na mídia; deixando, assim, a questão racial como secundária. Do mesmo modo, buscamos entender como a esfera da escola pública ganhou força para se tornar caput desta legislação.

Nesse sentido, nosso objetivo é observar como os parlamentares do Congresso Nacional pensam as ações afırmativas no ensino superior. Para tanto, foram analisados os conteúdos dos projetos de lei que ambicionaram a criação desse tipo de política. Buscamos, assim, contemplar as justificativas apresentadas pelos deputados e senadores na hora de protocolar os projetos. A obtenção dos dados ocorreu a partir da busca pelos termos "ações afirmativas" e "cotas" no site da Câmara dos Deputados Federais e do Senado. Após esses filtros, estabelecemos um recorte temporal entre o primeiro projeto, protocolado no ano de 1983 e o ano de 2012. A escolha deste último tem a ver com o ano de implementação da lei de cotas. É importante ressaltar que o debate não se encerra nesse momento, contudo, entendemos que o pós-lei acarreta outras discussões.

Valendo-se da metodologia qualitativa, em específico a análise de conteúdo, este artigo busca apreender os sentidos que são atribuídos as ações afirmativas quando um parlamentar apresenta um projeto de lei sobre o assunto. Afastado de uma análise subjetiva, a pesquisa foi desenvolvida a partir da investigação documental no qual duas questões são fundamentais para compreendê-la. A primeira entende 
o parlamentar como um tipo de "empreendedor de política" que visa criar uma coalizão para a aprovação do seu projeto (CAPELLA, 2016, p. 489). A segunda diz respeito a construção da burocracia através do papel e da escrita onde há uma escolha política do que será registrado ou não (HOYLER e CAMPOS, 2019, p.8).

Este trabalho está dividido em duas partes. Na primeira buscamos discutir o debate apresentado na esfera pública e no campo acadêmico sobre as ações afırmativas e como essa se torna uma política pública de fato. Já na segunda, fazemos uma análise das justificativas para criação das ações afirmativas apresentadas pelos parlamentares do Congresso Nacional no momento da apresentação de um Projeto de lei com a temática.

\section{O debate sobre Ações afirmativas e a transformação em política pública}

A primeira experiência de ação afırmativa ocorreu, em 1919, na Índia. Conhecida como "reservas", o sistema destinava 147 vagas no parlamento indiano para os Shudras ${ }^{6}$. Entretanto, é durante a década de 60, nos Estados Unidos, que a temática ganha força. É um momento de luta por direitos civis no país e o movimento negro surge como potência atuante ${ }^{7}$ (MOEHLECKE, 2002, p, 198). Em particular, a expressão "Affirmative Action" aparece pela primeira vez no decreto n 10.925 em 1961. O texto apresentava a seguinte redação "O contratante adotará uma ação afirmativa para assegurar que os candidatos sejam empregados, como também tratado durante o emprego, sem consideração a sua raça, credo, cor ou nacionalidade." (MEDEIROS, 2004, p. 122).

No Brasil, com mostrado por Alberti e Pereira (2006) após uma série de entrevistas com representantes do movimento negro, as reinvindicações por ações afırmativas ganharam força nos anos 2000. Estas foram impulsionadas por alguns movimentos importantes como a Conferência Nacional Contra o Racismo e a Intolerância, a Marcha Zumbi dos Palmares Contra o Racismo pela Cidadania e Vida e a III Conferência Mundial 
de Combate ao Racismo, Discriminação Racial, Xenofobia e Intolerância Correlata, conhecida como "Conferência de Durban".

Percebe se que a questão das cotas adquiriu uma dimensão muito importante para o próprio movimento negro, cujas lideranças passaram por um processo de maturação. Ou seja, depois de Durban, estando lançada a questão que tanta polêmica suscitou, foi necessário que as lideranças também se preparassem para o debate. Isso significa, mais uma vez, a formação de quadros capazes de implementar a bandeira que se tornou comum no movimento, atentando inclusive para os riscos da ascensão individualizada de estudantes cotistas (ALBERTI e PEREIRA, 2006, p.158).

Esse processo de amadurecimento corresponde à crítica feita pelo movimento negro em relação a modalidade de ações afırmativas conhecida como "cotas". Influenciados pela experiência estadunidense, grande parte dos quadros desse movimento desaprovavam o modelo; argumentando que esse gerava um individualismo que não era compatível com a luta histórica. A ideia de uma ação afırmativa, nesse âmbito, deveria vir de uma valorização do negro (ALBERTI; PEREIRA, 2006).

É nesse cenário que após dois meses da Conferência de Durban, o estado do Rio de Janeiro sancionou a lei n 3.708 que destinava 40\% de vagas para candidatos autodeclarados negros e pardos nas universidades estaduais ${ }^{8}$. No ano seguinte a Universidade do Estado da Bahia (UNEB) e Universidade Estadual do Mato Crosso do Sul (UEMS) aderem as ações afırmativas. Em 2003, a Universidade de Brasília se torna a primeira federal a criar esse mecanismo em seu vestibular.

Esse movimento levou as ações afırmativas no ensino superior para duas esferas. De um lado as universidades começaram a adotar a política de forma exponencial. De outro, a grande mídia e alguns intelectuais se mostraram totalmente contra a esse processo. Feres Júnior e Daflon (2015) demonstram a partir de análises dos jornais "O Clobo" e "Folha de São Paulo" que ambos publicaram amplamente notícias e notas de opinião contrária as cotas. No caso do "O Globo", foram 
publicados 132 editoriais dentre eles, "123 abertamente contrários, 5 ambivalentes e 4 que citavam de passagem as políticas sem proferir opinião explícita" (FERES JÚNIIR; DAFLON, 2015. P 247). No campo intelectual, o tema também foi amplamente debatido, em especial nas ciências sociais (CAMPOS, 2008; GOSS, 2009). Além disso, dois manifestos da sociedade civil organizada foram apresentados ao Congresso Nacional. O primeiro no dia 30 de junho de 2006 com 114 assinaturas contrárias as cotas. E outro na data de 5 de julho de 2006 com 582 assinaturas a favor da criação dessa política.

Em ambas as esferas os argumentos contrários as ações afirmativas permeavam a questão das cotas raciais. Em particular as concepções de que estas "criam/acirram o conflito racial", "tende a beneficiar classe média/elite negra", "são inconstitucionais" e "diminui a qualidade do ensino". Em contrapartida, os argumentos favoráveis versão especialmente sobre "capacitará os beneficiários a competir em igualdade", "tem estimulado o debate sobre as desigualdades raciais e desassocia cor a pobreza", "busca dirimir os efeitos da escravidão no presente" e "promove a mobilidade social de grupos discriminados" (CAMPOS e FERES JUNIOR, 2013, p. 14).

Nesse sentido, apesar da ação afırmativa poder ser mobilizada para qualquer grupo minoritário que esteja com dificuldade de acesso a algum bem público, a discussão na esfera pública se expandiu a partir das discussões sobre desigualdade de raça. Do mesmo modo, independente de apresentar diversas modalidades, como bônus, vagas suplementares, bolsas e empréstimos, a polemica se centrou na modalidade reserva de vagas que ficou popularmente conhecida como "cotas".

Assim, nosso objetivo com este artigo é tentar entender se esses dispositivos também foram acionados no Congresso Nacional. A escolha dessa esfera do Estado perpassa as discussões sobre políticas públicas, em especial a ideia de que essa é denominada a partir do que o governo decide ou não fazer (SOUZA, 2007, p. 62). Essa deliberação se desenvolve com base nas capacidades dos deputados e senadores 
de mobilizar recursos políticos e econômicos transformados em bens que serão distribuídos a população (EASTON, 1969).

Entendendo a política pública como um clico, aprová-la ou não é a primeira etapa para a sua realização. Nesse âmbito, utilizados o "ciclo das políticas públicas" para pensar nosso objeto. Inicialmente, essa teoria tinha como proposta entender a política pública por três eixos sequenciais: formulação, implementação e avaliação. Deste modo, a fase de formulação se constituí pela transformação de um problema em agenda política e a criação de uma solução. Por consequência, a implementação ocorre no momento que a política é colocada em prática. E, por fım, a avaliação consistiria em observar e analisar os resultados obtidos.

Com o amadurecimento do campo, esta estrutura foi redesenhada por alguns teóricos. A fase de "formulação", por exemplo, foi seccionada nas seguintes etapas: definição de agenda, identificação de alternativas, avaliação e seleção de opções como processos isolados (SOUZA, 2007, 60). Em adição, Stephen Ball e Richard Bowe (1992;1994) identificaram uma etapa anterior a formulação onde a produção da política pública ocorre a partir da intenção de fazê-la. Esse estágio foi denominado de intended policy. É importante ressaltar que a fluidez desse ciclo é questionada, deixando, assim, a ideia de que uma etapa pode acontecer conjuntamente com a outra (ARRETCHE, 2001, p.45). Contudo, neste presente artigo, utilizaremos o ciclo das políticas públicas como categoria analítica.

Nesse sentido, os projetos de lei analisados aqui se enquadram na fase da formulação, mais especificamente no momento da criação de alternativas para um problema. Ao analisarmos as justificativas apresentadas pelos parlamentares estamos propondo observar como esses enxergam o tema das ações afırmativas no ensino superior. Esse é o objetivo da próxima seção.

\section{As justificativas das ações afirmativas no Congresso Nacional}

As ações afırmativas no ensino superior ocorreram de duas maneiras. A primeira via resoluções das próprias universidades públicas 
e a segunda através de leis. Atualmente, no âmbito federal, está em vigência a lei n`12.711/12. Já na esfera estadual, encontramos 34 universidades com este tipo de política, sendo 17 instauradas a partir de resoluções dos Conselhos Universitários e 17 instituídas por leis estaduais (MACHADO, EURÍSTENES e FERES JÚNIOR, 2017, p. 9).

Quando advinda das universidades, as ações afırmativas são apreciadas pelos conselhos universitários. Já âmbito legislativo, antes de se aprovar uma lei, é necessário apresentar um projeto justificando a necessidade de sua anuência. É neste momento que os parlamentares mostram seus discursos em relação ao tema. Assim, este artigo propõe analisar os enunciados expostos no protocolamento dos projetos de lei que buscavam instituir ações afırmativas no ensino superior brasileiro. Entretanto, precisamos ressaltar que não estamos observando toda a tramitação destas propostas. Nesse sentido, buscamos realizar uma análise documental enquadrada apenas nas justificativas retratadas nos PLs.

Foram analisados 28 projetos de lei protocolados entre 1995 e 2012. Estas propostas foram encontradas na busca pelo termo "ações afirmativas" e "cotas" nos sites da Câmara dos Deputados Federais e do Senado e propomos o recorte temporal o momento pós promulgação da constituição de 1988 e 2012, ano da instituição da lei de cotas. A escolha deste último diz respeito a análise dos projetos de lei que vieram depois. Percebemos que essas propostas não tinham mais o objetivo de discutir ações afırmativas em si, mas apenas ampliar o direito, como por exemplo, os PLs n³ 3425, 3438, 3722, 3402, ambos de 2020 , que propunham ampliar as políticas de cotas para a pós-graduação.

Quanto aos projetos, percebemos que a temática é difusa em relação a partidos e a espectros ideológicos. Assim, 10 projetos foram apresentados pelo Partido do Movimento Democrático Brasileiro (PMDB), 6 pelo Partido dos Trabalhadores (PT), 4 pelo Partido da Social Democracia Brasileira (PSDB), 3 pelo Partido da Frente Liberal (PFL), 2 pelo Partido Democrático Trabalhista (PDT); e com respectivamente um projeto, o Poder Executivo ${ }^{10}$, Partido Trabalhista Brasileiro (PTB) e 
Partido Progressista Brasileiro (PPB). Diversas análises podem ser feitas com cruzamento desses dados, contudo, nosso objetivo aqui é observar mais profundamente as justificativas das ações afırmativas no Congresso Nacional e por isso, não conseguiremos esquadrinhar a discussão referente a partidos políticos.

No entanto, um fator relevante para o presente estudo é o grupo-alvo das ações afırmativas. Como apresentado anteriormente, esse tipo de política pode ser acionado para diferentes grupos que apresentem impedimento no acesso a determinados bens. Neste trabalho, em específico, as dificuldades de ingresso no ensino superior público. Assim, conforme a tabela 1 foram encontrados em 18 projetos ações afirmativas para estudantes de escolas públicas, dentre esses, um para alunos de escolas estaduais apenas. Por outro lado, encontramos em 5 projetos para pessoas negras, em 5 para indígenas e 5 para pessoas de baixa renda. Ademais, um projeto ainda propõe a política para pessoas que residam perto das universidades. É importante ressaltar que o valor total apresentado nessa variável não se traduz no número absoluto de projetos tento em vista que algumas propostas possuem mais de um grupo alvo. Por exemplo, o PL n³627/2004 do poder executivo no qual contempla estudantes de escolas públicas, negros e indígenas.

Tabela 1. Grupos-alvos das políticas de ações afirmativas mobilizado nos projetos de lei (Em absoluto) ${ }^{11}$

\begin{tabular}{l|c}
\hline GRUPO-ALVO & QUANTIDADE DE PROJETOS \\
\hline Estudantes de escolas públicas & 18 \\
\hline Negros & 5 \\
\hline Indígenas & 5 \\
\hline Residentes da localidade onde a universidade está & 1 \\
\hline
\end{tabular}

Fonte: Diários do Congresso Nacional (elaboração da autora)

Nesse sentido, podemos assinalar que a maioria dos parlamentares entendia que o grupo-alvo das ações afırmativas no ensino superior deveria ser os estudantes de escola pública. Entretanto, só observar 
a audiência não responde como essa política pública é considerada pelos proponentes. Separamos, assim, a análise das justificativas em dois grandes eixos. O primeiro observa a fundamentação da escolha do grupo-alvo. O segundo abrange a discussão sobre ações afirmativas de forma geral.

Quanto as justificativas para escolha dos grupos-alvos, percebemos que foram acionados seis argumentos: desigualdade de renda, desigualdade de raça, paradoxo do ensino superior público/privado, baixa qualidade da escola pública, desigualdade de acesso dos indígenas ao ensino superior e colocar como grupo alvo a escola pública evita critérios raciais. A tabela a seguir mostra a quantidade de vezes que esses fundamentos foram acionados.

Tabela 2. Quantidade de vezes que as justificativas sobre os grupos-alvos dos projetos foram acionadas (Em absoluto) ${ }^{12}$

\begin{tabular}{l|c}
\hline JUSTIFICATIVA & QUANTIDADE \\
\hline Desigualdade de renda & 19 \\
\hline Desigualdade racial & 6 \\
\hline Baixa qualidade da escola pública & 5 \\
\hline Desigualdade de acesso dos indígenas ao ensino superior & 5 \\
\hline Paradoxo do ensino superior público/privado & 3 \\
\hline Colocar como grupo alvo a escola pública evita critérios raciais & 2 \\
\hline
\end{tabular}

Fonte: Diários do Congresso Nacional (elaboração da autora)

A partir da tabela, percebemos que apesar do maior número de projetos contemplar os estudantes de escolas públicas como grupo-alvo, o debate levantado pelas justificativas se debruça na questão da desigualdade de renda. Dos 28 projetos, 19 mencionam esse ponto como sendo um impeditivo para o acesso à universidade. Nesse sentido, faz-se necessário uma análise aprofundada destes argumentos.

Os argumentos pautados na desigualdade de renda se debruçavam em duas perspectivas. A primeira salientava as estatísticas apresentadas sobre o ensino superior que mostravam esse como espaço ocupado por pessoas com renda alta. 
As estatísticas sócio econômicas e educacionais evidenciam que as chances de uma família pobre levar seu filho ou filha a entrar na universidade pública é da ordem de 0,5 por cento. E as famílias pobres são cerca de 60 por cento do total, em nosso País (BRASIL, 2003a, p.2)

O acesso à educação superior evidencia a profunda desigualdade social existente no País. Cerca de $48 \%$ dos alunos matriculados nas instituições de ensino superior provêm dos 10\% da população que dispõem de maior renda (BRASIL, 2003b, p.1)

A segunda enfatizava que os estudantes de baixa renda, por conta dos altos preços das escolas particulares e dos cursos preparatórios, não conseguiam competir no momento do vestibular. Assim, o poder aquisitivo, nesse argumento, está relacionado com a qualidade no ensino e, consequentemente, com o processo seletivo de acesso à universidade pública.

Os alunos de faixa de renda mais baixa, que frequentam o grau médio das escolas públicas, não têm como competir com os alunos de classes mais abastadas que frequentam "cursinhos preparatório" caríssimos, mas multo eficazes na consecução de uma alta porcentagem de aprovação nos vestibulares (BRASIL, 1999c, p.1)

A questão da qualidade no ensino da escola pública se torna recorrente em algumas propostas. Durante a análise, percebemos que cinco projetos apresentavam essa questão de forma mais direta e separada do contexto de classe. Por esse ângulo, a necessidade de ações afırmativas para estudantes desse segmento ocorreria somente pela precariedade do ensino básico público. E, apontava-se, portanto, que a saída para esse dilema deveria ser a melhoria da escola pública.

Se deve principalmente ao fato de que o ensino público é insuficiente, mal equipado, os professores são mal remunerados e o resultado disso é que os alunos das escolas públicas, paradoxalmente, são excluídos das universidades públicas. (BRASIL, 2002, p.2) 
A mudança deste quadro depende, fundamentalmente, de políticas educacionais de caráter distinto, mas complementares: uma, com efeito de médio prazo, é a melhoria da qualidade da educação básica nas escolas públicas, favorecendo o nível de competitividade de seus alunos nos processos seletivos para acesso à educação superior. (BRASIL, 2003c, p.1)

A escola pública, ainda aparece em um terceiro tipo de justificativa no qual chamamos aqui de "paradoxo do ensino superior público/ privado". Essa categoria engloba a perspectiva de que estudantes de escolas públicas acabam acessando o ensino superior via universidade privada, e, consequentemente, os estudantes de escolas privadas entram em universidades públicas (PAULA, 2008, p.220).

Concluído o segundo grau, surge então o grande gargalo, que é o vestibular para entrada na universidade. Milhares e milhares de alunos concorrem, poucos entram. Justamente neste momento, verifica-se a maior inversão de valores do sistema de ensino: os alunos que estudaram em estabelecimento particular, apesar do poder aquisitivo superior, ingressam em universidade pública, porque estão mais bem preparados, e os demais que frequentaram escola pública, que enfrentaram toda sorte de dificuldades, não conseguem lograr aprovação nos vestibulares das universidades públicas, restando-lhes, como opção, a universidade particular, se tiverem condições de pagar, ou a interrupção dos estudos. (BRASIL, 2004c, p. 1, grifo nosso)

No Brasil, encontramos, de um lado, as instituições universitárias públicas com alto referencial de qualidade, e de outro, as instituições particulares, oferendo ensino de baixo custo e algumas de qualidade duvidosa. As primeiras mantidas pelo Governo, são gratuitas e as segundas, mantidas por particulares são pagas; mas, as primeiras são frequentadas pelas classes mais abastadas, as elites, e as segundas, pelas classes mais proletárias. É uma situação perversa. (BRASIL, 1999C, p.2, grifo nosso) 
Como podemos observar essa justificativa engloba tanto a discussão de qualidade no ensino quanto a discussão de papel da universidade pública. Desta forma, quando o parlamentar manifesta que este fenômeno arrevesa os valores do sistema de ensino, objetiva afirmar que o ensino superior tem como função social a entrada de estudantes oriundos de todos os tipos de escola. E, nesse sentido, abarcar uma pluralidade de estudantes.

Do mesmo modo, a causa para tal acontecimento seria a baixa qualidade do ensino básico brasileiro. A justificativa aqui, se debruça sob o mesmo argumento apresentado na categoria "baixa qualidade da escola pública", contudo, há um novo fator relevante, a ida desses estudantes para a universidade particular. Por esse ângulo, os parlamentares entendem que os estudantes de escola pública possuem poder aquisitivo para arcar com as despesas ocasionadas por esse tipo de estudo e, consequentemente, se distanciam da alegação de baixa renda inserida nesse bloco.

Como podemos perceber, o vestibular das instituições de ensino superior públicas se torna um mecanismo importante para compreender as justificativas centradas em renda e na qualidade da escola pública. Na perspectiva dos proponentes dos projetos de lei este tipo processo seletivo amplia as desigualdades sociais. Por conseguinte, "O ideal, quando se possui um ensino fundamental e médio de boa qualidade, é a extinção do vestibular" (BRASIL, 1999a, p. 1)

O vestibular como impeditivo também aparece nos projetos onde é mobilizada a categoria "Desigualdade de acesso dos indígenas ao ensino superior". Nesse âmbito, os indígenas teriam dificuldades no acesso à universidade pública devido ao caráter elitista do vestibular no qual são cobrados conteúdos que não garantem a diversidade. Por exemplo, um vestibular onde se cobra língua portuguesa e língua inglesa faz com que o vestibulando indígena precise se submeter a avaliação de duas línguas estrangeiras. Esse tema já havia sido debatido amplamente na academia, entretanto, no Congresso Nacional é evi- 
denciado através de um debate sobre "melhor qualidade de vida". Esse argumento é um contrassenso as discussões acadêmicas nas quais se demonstrava a contribuição dos indígenas à universidade na garantia de uma pluralidade de saberes (DOS SANTOS e QUEIROZ, 2006; COHN e DAL'BÓ, 2016; DE SOUZA LIMA, 2007).

O acesso de parte da população indígena ao ensino superior é talvez uma das poucas possibilidades de que essa comunidade possa dar melhores condições de vida a seus pares e sobretudo, discernir, dentro de uma visão vinda de membros da própria sociedade indígena, de que destino seguir (BRASIL, 2003b, p. 3).

É importante ressaltar que no desenho final da lei de cotas federal os indígenas, pretos e pardos formaram uma subcota em conjunto por serem “minorias étnicas” (MIRANDA, 2018, p. 102). Todavia, quando observamos as justificativas dos projetos de lei, percebemos que o debate sobre os grupos ocorreu de forma distinta. Enquanto o argumento para a criação de ações afırmavas para indígenas se debruçava sobre as dificuldades do vestibular, o pressuposto para os negros ${ }^{13}$ se desenvolvia a partir do preconceito racial.

Somente no final do século passado, o Estado brasileiro passou a se preocupar com os efeitos do chamado racismo estruturante no perfil social e buscar mecanismos que dessem efetividade aos compromissos assumidos perante a comunidade internacional há quase quarenta anos. Esse atraso de décadas por si é suficiente para justificar a iniciativa de políticas de ações afırmativas no âmbito da educação, como as consignadas no presente Projeto de Lei. Entretanto, cumpre-nos acrescentar que o presente Projeto de Lei, adotando a política de cotas, o faz de forma racional distribuindo-as pela composição étnico racial das unidades federativas. (BRASIL, 2004a, p.1).

Igualmente ao ocorrido na mídia, o tema das ações afırmativa para negros não foi consensual no Congresso Nacional. As notícias apresentadas na seção anterior foram trazidas para os projetos de lei. Como 
o caso do $\mathrm{PL} \mathrm{n}{ }^{\circ} 479$ de 2008, protocolado no Senado, no qual trazia como justificativa uma cópia integral de um editorial do O Clobo assinado por Ali Kamel. Nesse, o parlamentar assinalava que ao instituir cotas raciais "se deixaria de fora os brancos pobres do Brasil" (BRASIL, 2008, p.2). Dessarte, era mais fácil inverter a situação e instituir ações afirmativas para pessoas com baixa renda.

Ao longo da análise percebemos que os parlamentares criavam saídas para evitar a "questão racial". Para tanto, a estratégia deveria ocorrer destinando vagas para estudantes de escola pública. Nessa acepção, os deputados federais e senadores associavam livremente esses estudantes à baixa renda e a raça, entendendo, portanto, o ensino público como um espaço majoritário de pessoas negras com baixo poder aquisitivo.

Ao mesmo tempo, este projeto atende ao sistema de cotas para os negros em universidades públicas, exatamente porque são eles os que mais compõem as camadas de renda inferior e, portanto, os que mais utilizam a rede pública de ensino. Mais ainda: evita-se a dificuldade natural de definir quem é e quem não é negro em um país marcado pela miscigenação de raças, acabando com um processo de seleção que pode ser, em alguns casos, discriminatório. (BRASIL, 2004c, p.2)

Nossa posição é a de que a discriminação se concentra no fator econômico, atingindo por consequência as etnias desfavorecidas e os estudantes de famílias que não conseguem matricular seus filhos em escolas particulares, que se orientam para a preparação de seus alunos para os vestibulares. (BRASIL, 2008b, p.1)

Como podemos ver, ao longo da apresentação desses projetos, a escola pública vai ganhando sua centralidade na justifıcativa. Isso responde ao cruzamento entre grupo-alvo e justificativa no qual iniciamos o presente trabalho. Apesar do entendimento dos parlamentares de que a raça e a classe eram fatores geradores da desigualdade, o que deveria ser considerado para esses era, em grande medida, a má qualidade no ensino público. Do mesmo modo, se tornava um recurso para impedir que o critério raça fosse englobado na política. 
Em alguma proporção esse debate acabou ganhando força dentro do Congresso Nacional. Como consequência disso, temos o caput da lei $n^{\circ}$ 12.711/12 onde se reserva de "no mínimo 50\% (cinquenta por cento) de suas vagas para estudantes que tenham cursado integralmente o ensino médio em escolas públicas" (BRASIL, 2012). Como efeito, estudantes bolsistas de escolas particulares não podem concorrer a este tipo de política. O que nos leva ao argumento de que a questão da “má qualidade no ensino básico público' também acabou sendo incorporada a esta discussão.

Quanto ao segundo eixo de análise do presente artigo, procuramos compreender como os parlamentares justificavam as ações afırmativas em si. Encontramos três principais argumentos. O primeiro pautado na ideia de que essas são mecanismos constitucionais de inclusão. O segundo observava as experiências de sucesso em universidades e percebiam que está política deveria ser ampliada. A terceira debruçava no ideal de democratização do ensino superior.

As ações afırmativas como dispositivo constitucional foi amplamente mobilizada pelos parlamentares. Pode-se argumentar que essa foi uma ferramenta acionada com objetivo assegurar a aprovação pela Comissão de Constituição e Justiça de suas respectivas casas tendo em vista que o tema ainda não havia sido debatido no STF. Do mesmo modo, percebe-se que ao acionar a legalidade das ações afırmativas, os deputados federais e senadores buscam encerrar o debate sobre “descriminação positiva” trazido pela temática.

Alguns argumentam que a reserva de vagas fere um princípio de direitos. No entanto, ainda que possa parecer contraditório, para se alcançar o efetivo cumprimento do princípio constitucional da igualdade de acesso é necessário introduzir medidas que garantam a todos, e não apenas a alguns oriundos das rendas mais altas, o direito de ocupar uma vaga na educação pública de nível superior (BRASIL, 2007a, p.1). 
Além disso, havia um entendimento das ações afirmativas como um modelo de democratização do ensino superior público. É interessante ressaltar que apenas um projeto assinalava que o cenário ideal era a extinção do vestibular. Nesse sentido, o entendimento sobre democratizar estava pautado na manutenção do mérito e o limitado número de vagas nas universidades públicas. Esse, portanto, seria um melhor mecanismo para ampliação do acesso.

\section{Conclusão}

No presente artigo procuramos observar as justificativas para a implementação de ações afırmativas no ensino superior brasileiro mobilizadas pelos parlamentares do Congresso Nacional. Para tanto, analisamos 28 projetos de lei que possuíam esse intuito. Nosso principal foco de estudo foram as justificativas e os grupos-alvos escolhidos pelos deputados federais e senadores.

$\mathrm{Na}$ análise, percebemos que os parlamentares associam livremente escola pública como um espaço de desigualdade de renda e entendem que em nenhuma hipótese um indivíduo com alta renda poderia acessar esse tipo de ensino. A justificativa para tal afırmação é o fato de havia uma percepção de que o ensino público é, majoritariamente, de má qualidade. Nesse sentido, a escola pública ganhou centralidade na maioria dos projetos.

Assim, compreendemos que a luta histórica do movimento negro para a criação de ações afirmativas perdeu espaço no Congresso Nacional. A ideia de desigualdade de raça centrada no racismo estrutural brasileiro pouco foi acionada pelos parlamentares. Ao contrário, a maioria dos projetos apresentava que a questão racial deveria ser evitada no Brasil. Esse fundamento refletiu, em alguma medida, os argumentos apresentados na grande mídia. A alegação de um país miscigenado, uma democracia racial, onde o problema de acesso ao ensino superior está na qualidade de ensino básico público e não no preconceito de cor, adquire uma roupagem positiva. Daí reservar vagas para estudantes escola pública resolveria todo esse emaranhado problemático. 
Percebemos, em adição, que os deputados federais e senadores compreendiam as ações afırmativas como um mecanismo constitucional de garantia de direitos. Outrossim, esse tipo de política permitia a democratização do ensino superior público. Este último entendido como um espaço elitizado onde apenas estudantes mais abastados teriam acesso. Nesse âmbito, os parlamentares percebiam que a principal estrutura de elitização era o vestibular. Entretanto, o tema se desenvolve de forma complexa tendo em vista que apenas um projeto assinala que o melhor caminho seria a abolição do vestibular, em contrapartida 15 PLs justificam a manutenção do mérito.

Este trabalho, portanto, tentou aprofundar essa complexa temática das ações afirmativas na perspectiva dos parlamentares do Congresso Nacional. Entende-se que ao fazermos um estudo aprofundado de um determinado contexto, deixamos de fora outras questões. No caso do presente estudo precisaríamos também observar quem são esses deputados e senadores e quais a discussão envolvida dentro dos partidos. Contudo, não deixamos de observar as nuances que a política adquire ao ser debatida nessa esfera legislativa.

\section{Referências}

ALBERTI, Verena; PEREIRA, Amilcar. A defesa das cotas como estratégia política do movimento negro contemporâneo. Revista Estudos Históricos, Rio de Janeiro, v. 1, n. 37, p. 143-166, 2006.

BALL, Stephen. Educational reform: a critical and post-structural approach. Buckingham: Open University Press, 1994.

BALL, Stephen J. BOWE, Richard. Subject departments and the "implementation" of National Curriculum policy: an overview of the issues. Journal of Curriculum Studies, v. 24, n. 2, p. 97-115, 1992.

BITTAR, Mariluce; ALMEIDA, Carina de. Mitos e controvérsias sobre a política de cotas para negros na educação superior. Educar em revista, Curitiba, n. 28, p. 141-159, 2006.

BRASIL. Constituição da República Federativa do Brasil. Brasília, DF: Senado Federal: Centro Gráfico, 1988. BRASIL. Congresso Nacional. Senado. Projeto 
de lei $n^{\circ}$ 13/95. Brasília, 1995a. Disponível em: <https://www25.senado.leg. br/web/atividade/materias/-/materia/24247>. Acesso em: outubro 2020.

BRASIL. Congresso Nacional. Senado. Projeto de lei n 14/95. Brasília, 1995b. Disponível em: <https://www25.senado.leg.br/web/atividade/materias/-/ materia/24291> Acesso em: outubro 2020.

BRASIL. Congresso Nacional. Câmara dos Deputados. Projeto de lei $n^{\circ}$ 79/99. Brasília, 1999a. Disponível em: <http://imagem.camara.gov.br/Imagem/d/ pdf/DCD16MAR1999.pdf\#page=78> Acesso em: outubro 2020.

BRASIL. Congresso Nacional. Senado. Projeto de lei n 650/1999. Brasília, 1999b. Disponível em: <https://www25.senado.leg.br/web/atividade/materias/-/materia/42616>. Acesso em: outubro 2020.

BRASIL. Congresso Nacional. Câmara dos Deputados. Projeto de lei $n^{\circ}$ 1447/99. Brasília, 1999c. Disponível em: <https://legis.senado.leg.br/diarios/ ver/1399?sequencia=13> Acesso em: outubro 2020.

BRASIL. Congresso Nacional. Senado. Projeto de lei $n^{\circ}$ 298/1999. Brasília, 1999d. Disponível em: <https://legis.senado.leg.br/diarios/ver/12652?sequencia=61> Acesso em: outubro 2020.

BRASIL. Congresso Nacional. Câmara dos Deputados. Projeto de lei $n^{\circ}$ 2069/99. Brasília, 1999e. Disponível em: <http://imagem.camara.gov.br/ Imagem/d/pdf/DCD18NOV1999. pdf\#page=195> Acesso em: outubro 2020.

BRASIL. Congresso Nacional. Câmara dos Deputados. Projeto de lei $n^{\circ}$ 2486/00. Brasília, 2000a. Disponível em: <http://imagem.camara.gov.br/ Imagem/d/pdf/DCD03MAR2000.pdf\#page=73> Acesso em: outubro 2020.

BRASIL. Congresso Nacional. Câmara dos Deputados. Projeto de lei n 2772/00. Brasília, 2000b. Disponivel em: <http://imagem.camara.gov.br/montaPdf.asp? narquivo=DCD19ABR2000.pdf\&npagina=139> Acesso em: outubro 2020.

BRASIL. Congresso Nacional. Senado. Projeto de lei $n^{\circ}$ 135/2000. Brasília, 2000c. Disponivel em: <https://legis.senado.leg.br/diarios/ver/12652?sequencia=61 $>$. Acesso em: outubro 2020.

BRASIL. Congresso Nacional. Câmara dos Deputados. Projeto de lei n ${ }^{\circ}$ 4784/01. Brasília, 2001a. Disponível em: <https://www.camara.leg.br/proposicoesWeb/ fichadetramitacao?idProposicao=29196> Acesso em: outubro 2020.

BRASIL. Congresso Nacional. Câmara dos Deputados. Projeto de lei $n^{\circ}$ 5062/01. Brasília, 2001b. Disponível em: <http://imagem.camara.gov.br/ Imagem/d/pdf/DCD14ACO2001. pdf\#page=62> Acesso em: outubro 2020. 
BRASIL. Congresso Nacional. Câmara dos Deputados. Projeto de lei n 5325/01. Brasília, 2001c. Disponível em: <https://www.camara.leg.br/proposicoesWeb/ fichadetramitacao?idProposicao=33547> Acesso em: outubro 2020.

BRASIL. Congresso Nacional. Câmara dos Deputados. Projeto de lei n 5338/01. Brasília, 2001d. Disponível em: <https://www.camara.leg.br/proposicoesWeb/ fichadetramitacao?idProposicao=33953> Acesso em: outubro 2020.

BRASIL. Congresso Nacional. Senado. Projeto de lei $n^{\circ}$ 14/2002. Brasília, 2002. Disponível em: <https://www25.senado.leg.br/web/atividade/materias/-/materia/49504>. Acesso em: outubro 2020.

BRASIL. Congresso Nacional. Câmara dos Deputados. Projeto de lei $n^{\circ}$ 615/03. Brasília, 2003a. Disponivel em: <https://www.camara.leg.br/ proposicoesWeb/fichadetramitacao?idProposicao=109413> Acesso em: outubro 2020.

BRASIL. Congresso Nacional. Câmara dos Deputados. Projeto de lei n 1313/03. Brasilia, 2003b. Disponível em: <https://www.camara.leg.br/proposicoesWeb/fichadetramitacao?idProposicao=121207> Acesso em: outubro 2020.

BRASIL. Congresso Nacional. Câmara dos Deputados. Projeto de lei n 1188/03. Brasília, 2003c. Disponível em: <https://www.camara.leg.br/proposicoesWeb/ fichadetramitacao?idProposicao=118404> Acesso em: outubro 2020.

BRASIL. Congresso Nacional. Câmara dos Deputados. Projeto de lei n 1335/03. Brasilia, 2003d. Disponível em: <https://www.camara.leg.br/proposicoesWeb/fichadetramitacao?idProposicao=118404> Acesso em: outubro 2020.

BRASIL. Congresso Nacional. Senado. Projeto de lei $n^{\circ}$ 61/2003. Brasília, 2003e. Disponível em: <https://www25.senado.leg.br/web/atividade/materias/-/materia/55436>. Acesso em: outubro 2020.

BRASIL. Congresso Nacional. Senado. Projeto de lei $n^{\circ}$ 215/2003. Brasília, 2003f. Disponível em: <https://www25.senado.leg.br/web/atividade/materias/-/materia/58271>. Acesso em: outubro 2020.

BRASIL. Congresso Nacional. Câmara dos Deputados. Projeto de lei n ${ }^{\circ}$ 3627/04. Brasília, 2004a. Disponível em: <https://www.camara.leg.br/proposicoesWeb/ fichadetramitacao?idProposicao=254614> Acesso em: outubro 2020.

BRASIL. Congresso Nacional. Câmara dos Deputados. Projeto de lei n 3571/04. Brasilia, 2004b. Disponível em: <https://www.camara.leg.br/proposicoesWeb/fichadetramitacao?idProposicao=253804> Acesso em: outubro 2020. 
BRASIL. Congresso Nacional. Câmara dos Deputados. Projeto de lei n ${ }^{\circ}$ 3004/04. Brasilia, 2004c. Disponível em: <https://www.camara.leg.br/proposicoesWeb/ fichadetramitacao?idProposicao=154437> Acesso em: outubro 2020.

BRASIL. Congresso Nacional. Câmara dos Deputados. Projeto de lei $n^{\circ}$ 14/07. Brasília, 2007a. Disponível em: <https://www.camara.leg.br/ proposicoesWeb/fichadetramitacao?idProposicao=339973> Acesso em: outubro 2020.

BRASIL. Congresso Nacional. Câmara dos Deputados. Projeto de lei n ${ }^{\circ 330 / 07 .}$ Brasilia, 2007b. Disponível em: <https://www.camara.leg.br/proposicoesWeb/fichadetramitacao?idProposicao=339973> Acesso em: outubro 2020.

BRASIL. Congresso Nacional. Senado. Projeto de lei $n^{\circ}$ 479/08. Brasília, 2008a. Disponível em: <https://www25.senado.leg.br/web/atividade/materias/-/materia/88773>. Acesso em: outubro 2020.

BRASIL. Congresso Nacional. Senado. Projeto de lei $n^{\circ}$ 344/08. Brasília, 2008b. Disponível em: <https://www25.senado.leg.br/web/atividade/materias/-/materia/87354>. Acesso em: outubro 2020.

BRASIL. Congresso Nacional. Lei $n^{\circ}$ 12.711, de 29 de agosto de 2012. Dispõe sobre o ingresso nas universidades federais e nas instituições federais de ensino técnico de nível médio e dá outras providências. Brasília, 2012. Disponível em: https://bit.ly/1nOFDPs. Acesso em: novembro de 2020.

CAMPOS, Luiz Augusto. As trocas de acusações entre intelectuais na controvérsia pública acerca das cotas raciais. Latitude, Alagoas, v. 2, n. 2, p. 68-92, 2008.

CAMPOS, Luiz Augusto; FERES JÚNIOR, João. A Folha de S. Paulo e as ações afirmativas: dez anos de cobertura (2001-2011). Textos para discussão GEMAA (IESP-UERJ), n. 3, 2013, pp. 1-18.

CAPELLA, Ana Cláudia. Um estudo sobre o conceito de empreendedor de políticas públicas: Ideias, Interesses e Mudanças. Cad. EBAPE. Rio de Janeiro, v. 14, n. spe, p. 486-505, 2016.

COHN, Clarice; DAL'BÓ, Talita. Ingresso de indígenas em cursos regulares nas universidades e desafios da interculturalidade: o caso da UFSCar. In: Oliveira, Lucia (org.). A questão indígena no ensino superior. Cadernos GEA, Rio de Janeiro, n. 10, p. 27-37, 2016.

DE SOUZA LIMA, Antonio Carlos. Educação superior para indígenas no Brasil sobre cotas e algo mais. CLACSO. Buenos Aires, 2007. 
DOS SANTOS, Jocélio Teles; QUEIROZ, Delcele Mascarenhas. Vestibular com cotas: análise em uma instituição pública federal. Revista USP, n. 68, p. 58-75, 2006

EASTON, David. Esquema para el análise politica. Buenos Aires: Amarroutu, 1969. FERES JÚNIOR, João.; DAFLON, Veronica. A nata e as cotas raciais: genealogia de um argumento público. Opinião Pública, Campinas, SP, v. 21, n. 2, p. 238267, 2015.

FONSECA, Dagoberto José. Políticas públicas e ações afirmativas. São Paulo: Selo Negro, 2009.

COSS, Karine Pereira. Retóricas em disputa: o debate intelectual sobre as políticas de ação afirmativa para estudantes negros no Brasil. Ciências Sociais Unisinos, v. 45, n. 2, p. 114-124, 2009.

HOYLER, Telma; CAMPOS, Pedro. A vida política dos documentos: notas sobre burocratas, políticas e papéis. Rev. Sociol. Polit. Curitiba, v. 27, n. 69, 2019.

MACHADO, Marcell; EURÍSTENES, Poema; FERES JúNIOR, João. Políticas de ação afirmativa nas universidades estaduais (2017). Levantamento das políticas de ação afırmativa (GEMAA), IESP-UERJ, pp. 1-26.

MEDEIROS, Carlos Alberto. Ação Afırmativa no Brasil - Um Debate em Curso, in: SALES, Augusto dos Santos (org.). Ações Afirmativas e Combate ao Racismo nas Américas, Brasília: MEC/SECAD, 2005.

MEDEIROS, Carlos Alberto. Na lei e na raça: legislação e relações raciais, Brasil-Estados Unidos. Rio de janeiro: DP\&A Editora, 2004.

MIRANDA, Luma Doné. Ações Afirmativas no Ensino Superior: O Debate no Congresso Nacional. 2018. 142p. Dissertação (Mestrado em Ciências Sociais) - Programa de Pós-Graduação em Ciências Sociais, Universidade do Estado do Rio de Janeiro, Rio de Janeiro, 2018.

MOEHLECKE, Sabrina. Ação afirmativa: História e debates no Brasil. Cad. Pesquisa. São Paulo, n. 117, p. 197-217, 2002.

PAULA, Lucília Augusta Lino de. Relações raciais e desigualdade: resistências à política de cotas na universidade. In: SYSS, Ahyas. Diversidade étnico-racial e educação superior brasileiro: experiências de intervenção. Rio de Janeiro: Quartet, p. 219-240, 2008.

SOUZA, Celina. Estado da Arte da Pesquisa em Políticas Públicas. In: HOCHMAN, Gilberto; ARRETCHE, Marta; MARQUES, Eduardo. Políticas públicas no Brasil. SciELO-Editora FIOCRUZ, 2007. 
WEDDERBURN, Carlos. Do marco histórico das políticas públicas de ações afirmativas-perspectivas e considerações. In: SANTOS, Sales Augusto dos. Ações afirmativas e combate ao racismo nas Américas. Brasília: Ministério da Educação, Secretaria de Educação Continuada, Alfabetização e Diversidade, p. 313-341, 2005.

\section{Notas}

1 Doutoranda no Programa de Pós-graduação em Ciências Sociais da Universidade do Estado do Rio de Janeiro, Brasil. ORCID: https://orcid.org/00000002-9644-185X E-mail: lumadonemiranda@gmail.com. Agradeço a Coordenação de Aperfeiçoamento de Pessoal de Nível Superior - CAPES pelo apoio a presente pesquisa.

2 Como a Orquestra Afro-Brasileira, criada em 1942 por Abigail Moura; o Teatro Popular Brasileiro, fundado em 1943 por Solano Trindade; a União dos Homens de Cor, iniciada em Porto Alegre, em 1943; o Teatro Experimental do Negro (TEN), criado em 1944 por Abdias do Nascimento; Comitê Democrático Afro-Brasileiro, instituído em 1946, e a companhia afro-brasileira de dança Brasiliana, fundada em 1949 (ALBERTI e PEREIRA, 2006, p.144)

3 Entendemos aqui o termo "negros" como a soma de pretos e pardos.

4 Doravante PL

5 Em 2016 a lei foi modificada agregando também pessoas com deficiência (Lei $n^{\circ}$ 13.409, de 2016)

6 Ou Dalits, podendo ser traduzido como "os intocáveis", está inserido no sistema de castas indiano no qual há uma estrutura hierarquia social inserida nos conceitos religiosos do hinduísmo. "Esse sistema se articula em torno de conceitos de superioridade" e "inferioridade", de "pureza" e de "impureza", que envolvem não somente critérios religiosos, mas também sóciorraciais, tanto que, até hoje, as castas "superiores" (savarnas) se definem em relação a uma origem ariana."(WEDDERBURN, 2007, p. 308)

7 Podemos citar alguns nomes aqui como o de Martin Luther King, Martin Luther King Jr., Angela Davis, William Edward Burghardt Du Bois, além dos os movimentos do Partido dos Panteras Negras, o Movimento do Niagara e o Movimento Black Power.

8 A universidade já tinha sancionado uma lei no ano anterior no qual a reserva de vagas se destinava apenas à candidatos oriundos de escola pública. 
9 O trecho correspondente na tradução é "política pretendida".

10 No ano do protocolamento deste projeto, o Poder executivo pertencia ao Partido dos Trabalhadores tendo como presidente Luiz Inácio Lula da Silva.

O valor não corresponde ao total de 28 projetos porque algumas proposições destinavam ações afirmativa para dois ou mais grupos.

11 O valor não corresponde ao total de 28 projetos porque alguns argumentos foram apresentados em mais de um projeto.

12 Os parlamentares mobilizaram apenas o termo "negros", não foi encontrado a nomenclatura "Pretos e Pardos" utilizada pelo Instituto Brasileiro de Geografia e Estatística (IBCE). 